\title{
CFD Analysis of Localised Crud Effects on the Flow of Coolant in Nuclear Rod Bundles
}

\author{
N. Cinosi, S.P. Walker \\ Mechanical Engineering Department \\ Imperial College, London \\ n.cinosi@imperial.ac.uk
}

It has been suggested that crud deposits on a number of adjacent fuel rods might reduce coolant flow rates in associated sub-channels. Such reduced flow rates could then worsen thermal-hydraulic conditions, such as margin to saturated boiling, fuel surface temperature, and the DNB ratio. We report the results of a detailed computational fluid dynamics study of the flow pattern in a partially-crudded rod bundle. Values obviously depend on, for example, the thickness of crud assumed, but sub-channel flow rate reductions of $\sim 10 \%$ were predicted by this analysis. However, this mass flow rate reduction was found to be more than offset by improved heat transfer induced by the relatively rough surface of the crud. Cladding temperatures were predicted to be essentially unchanged, and the DNBR was similarly little altered. We conclude that such flow reduction and diversion is not likely to be of concern.

\section{INTRODUCTION}

This paper reports an investigation into the local reduction of coolant flow around clusters of crud coated fuel rods, which it has been suggested might reduce thermal margins locally [1].

The coolant in a PWR is water at $\sim 15.5 \mathrm{MPa}, \sim 300 \mathrm{C}$, containing dissolved ionic and molecular species and suspended particulates. Some of these are deliberately added, whilst others are the result of corrosion of the alloys used to construct the primary circuit.

There is a tendency for some of these materials to leave solution, and to form a solid deposit on the surface of the fuel cladding, particularly where boiling occurs on the cladding. Such deposits, termed "crud", have a variety of undesirable effects on the performance of the plant [2-6]. The purpose of this present paper is to report a study into the thermal-hydraulic consequences of crud deposits extending for only a small portion of the length of a contiguous collection of fuel rods, such that both radially and axially the crud-coated region is surrounded by an un-crudded region. The postulate behind this study is that the increased resistance to flow in the crudded sub-channels might cause flow diversion into adjacent smooth sub-channels, reducing thermal hydraulic margins in the crudded region.

The reasons for the formation of crud are incompletely understood. The contact surface of the primary coolant in a typical 4 loop PWR is approximately $25,000 \mathrm{~m}^{2}$ in extent, made up roughly of $60 \%$ steam generator tubing and $25 \%$ fuel cladding, with the remainder being the reactor vessel, connecting pipe work, and other components.

Nickel based alloys are used for the steam generator, zirconium alloys for the fuel clad and stainless steel alloys for the majority of the other components. Corrosion of the nickel alloy and steel components leads to the release of nickel and iron ions that can pass into solution as soluble species or if the solution is saturated can precipitate out to form particulate material [7]. The main solid phases that are found in the coolant, in fuel crud and on ex-core surfaces, are mixed nickel-iron spinel oxides (for example trevorite, $\mathrm{NiFe}_{2} \mathrm{O}_{4}$ ), nickel metal and nickel oxide (NiO). Only a very small 
fraction of these corrosion products are removed by the PWR plant water treatment system and most remain in the primary system to distribute over the various surfaces present [8].

The formation of crud leads to various undesirable consequences.

Crud-induced power shift: A important solute added to the coolant is boric acid, and the precipitation of this in the crud leads to locally increased neutron absorption and power reduction. This 'crud induced power shift', (CIPS) poses considerable operational and commercial problems for plants with significant crud deposits $[4,5]$. Fission rates are reduced locally, resulting in station electrical output reductions of several percent.

Increased fuel failure rates: A second important consequence of crud can be increased cladding corrosion, as zircalloy corrosion rates can double for each $15 \mathrm{C}$ temperature increase, and temperature increases considerably above this can be caused by crud deposits. Increasing concentrations of species such as lithium ions (which are added the coolant) in the crud also increased fuel clad corrosion rates [9, 10]. There is a marked association between crud deposits and some classes of fuel failure [11]. These effects are accentuated by the economic pressure to achieve higher power output and longer usage of fuel.

Modification of critical heat flux: Avoiding critical heat flux (CHF), and hence a good ability to predict $\mathrm{CHF}$, is fundamental to the thermal-hydraulic design of the PWR, for both optimization and safety. Current indications are that crud radically changes the mechanism of heat transfer, making values for CHF predicted for the wrong mechanism of dubious use [3,12]. This is not incorporated in current analyses at all well. There are some grounds to believe that crud increases CHF values [1,6], but a sound understanding of the mechanism is really needed before reliance on this is prudent.

Increased operator radiation doses: Crud present on the fuel cladding can be activated by the fission neutrons to form radioactive elements such as cobalt 58 and 60 . These, and other isotopes, are high energy gamma and beta emitters, that can be released from the core and deposited on surfaces outside the core region where maintenance work is required. Increased levels of crud and increased crud residence times in the core means potential higher radiation doses for staff working at the plant, providing a further incentive to understand crud in PWR systems.

Fuel crud morphology is very varied, as indeed is its chemical composition, but it is typically found as a porous, low-density, deposit on the top part of the fuel pins [2]. Measurements and analyses of crud are made following reactor shut down, during which the temperature has been reduced and the plant has generally undergone a mild chemical cleaning process using increased boric acid concentrations and hydrogen peroxide. There is therefore considerable uncertainty as to just how representative are crud property observations of the property values during normal power operations. Crud (if found) is typically in deposits some tens of microns thick, with on rare occasions deposits of more than 100 microns being found. Besides being 'homogeneously' porous with fine scale porosity, typical cruds are penetrated by large 'chimney-like' pores, that generally penetrate all or most of the way through the crud to the fuel clad surface [13].

Figure 1 shows typical crud deposits, with the chimneys clearly visible, and Figure 2 shows sections through the crud, again with chimneys visible. 


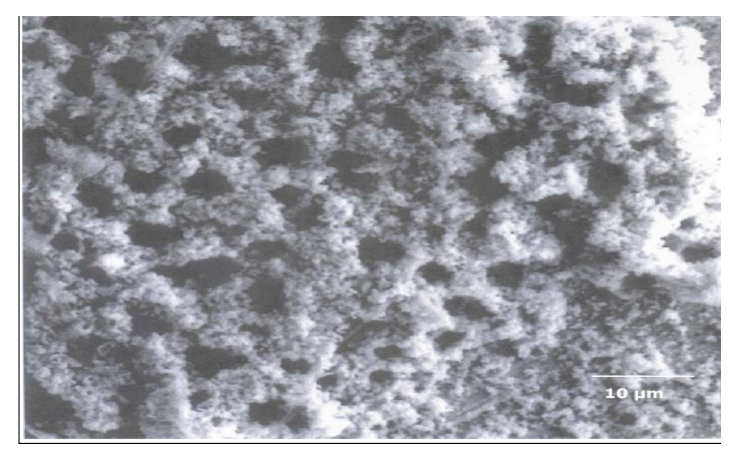

Figure 1: Crud deposits, showing the chimneys [5]
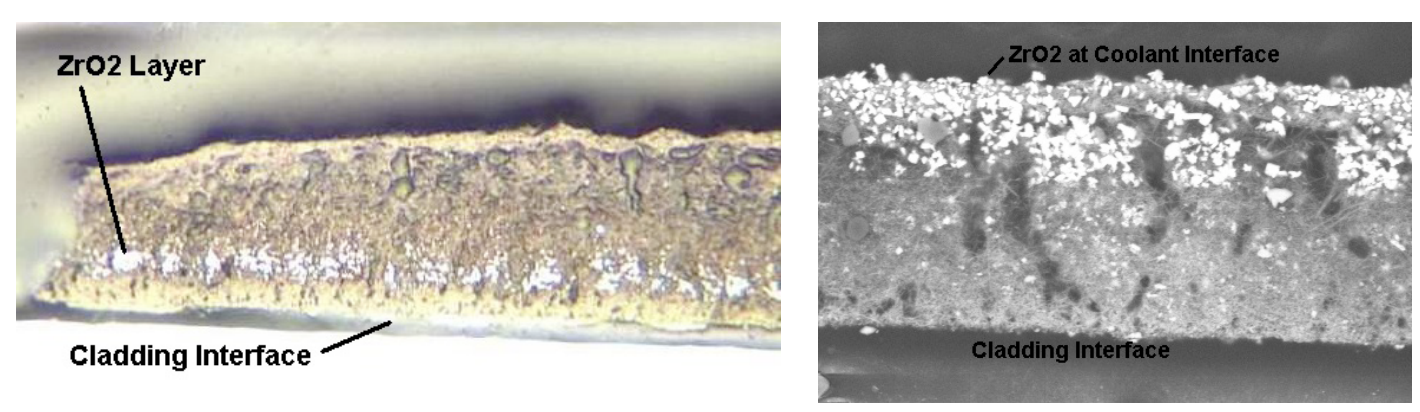

Figure 2: Cross sections through crud, with the chimneys visible [14]

Plainly, the crud can present a much rougher surface over which the coolant flows than does the normal relatively smooth zirconium oxide. Increased surface roughness might be expected to increase the rate of axial pressure drop in a crudded sub-channel, and thereby induce diversion of the coolant flow into adjacent subchannels should they be un-crudded. A reduced mass flow rate in the crudded subchannels might change the heat transfer coefficient in these channels, and the reduced mass flow rate could also cause the axial rate of coolant temperature rise to increase, reducing margins to boiling and so on. Buongiorno [1] recognized the importance of crud surface roughnesses in altering the process of heat removal and the consequent effects on the safety margin of LWRs. His analysis focused on the microscopic favorable formation of bubbles at the micro-cavities (asperities) of the crud surface. These crud-induced bubbles are responsible for the creation of local turbulences, which in turn, enhances the heat transfer in proximity of the fuel walls.

The present paper aims to investigate similar effects, but from a macroscopic point of view. The purpose of the present study is to investigate whether or not the variation in flow resistance laterally across the core causes a significant redistribution in the coolant flow. In particular, in the crudded cluster of rods, where flow is reduced, are parameters such as fuel temperature, local sub-cooled nucleate boiling rate, and DNB margins worsened?

The paper is structured as follows: Section 2 describes the geometrical and physical parameters involved in the analysis. Section 3 illustrates the overall methodology applied to link the hydraulic effects of roughness to the CHF. Section 4 and 5 explain in details the thermo-hydraulic computational analysis and the various steps of the evaluation procedure underlying the methodology, respectively. Section 6 presents 
the numerical results, with discussions of the predictions made. Conclusions are drawn, and further work identified, in Section 7.

\section{GEOMETRICAL AND PHYSICAL PARAMETERS}

\subsection{CRUD SURFACE}

Once formed, the layer of crud presents a highly irregular top surface with a nonuniform distribution of roughness, Figure 3. It should be noted there is much uncertainty in our knowledge of the topography of crud: during normal operation it is of course in very hot water, at $15 \mathrm{MPa}$, but in practice can only be examined in the laboratory after a period of cooling, in unpressurised water. Notwithstanding this, the evidence we have suggests that crud can be 'rough', with peaks and troughs of such roughness reaching heights of perhaps up to 20 microns; Figure 4.

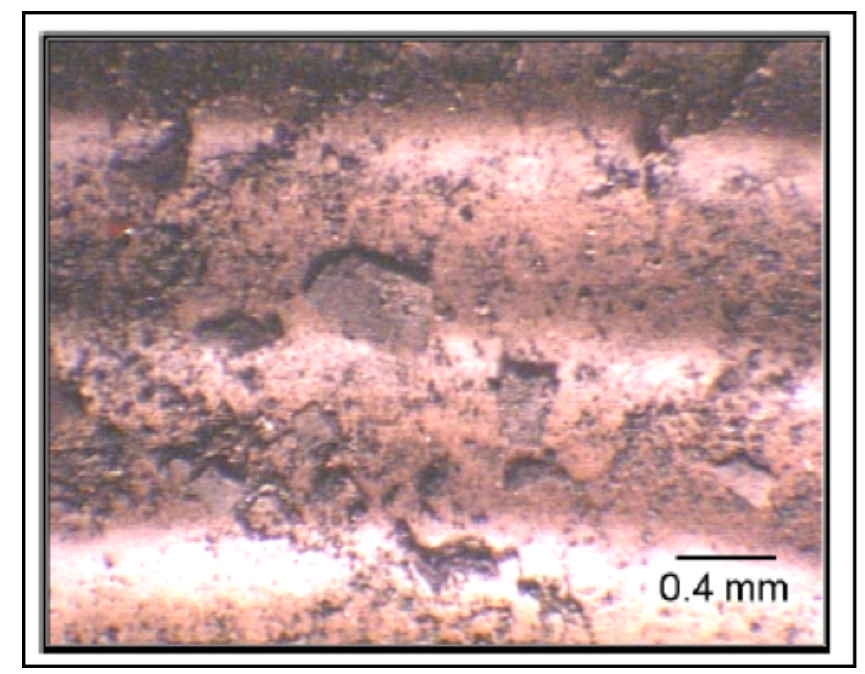

Figure 3: Highly irregular top surface of crud [14]

\subsubsection{EQUIVALENT SAND GRAIN ROUGHNESS}

Any naturally-occurring rough surface is virtually unique in its characteristics, and a large number of parameters could be used to describe the features of a given surface roughness. Given the infinite range of shapes and distributions of the asperities that may constitute a rough surface, the most obvious parameter to be considered is the average height of the roughness elements, where average is usually meant as a root-mean-square $(r m s)$ value. This parameter is called the geometric roughness height and it is used throughout the paper as an indication of the measure of the roughnesses. 


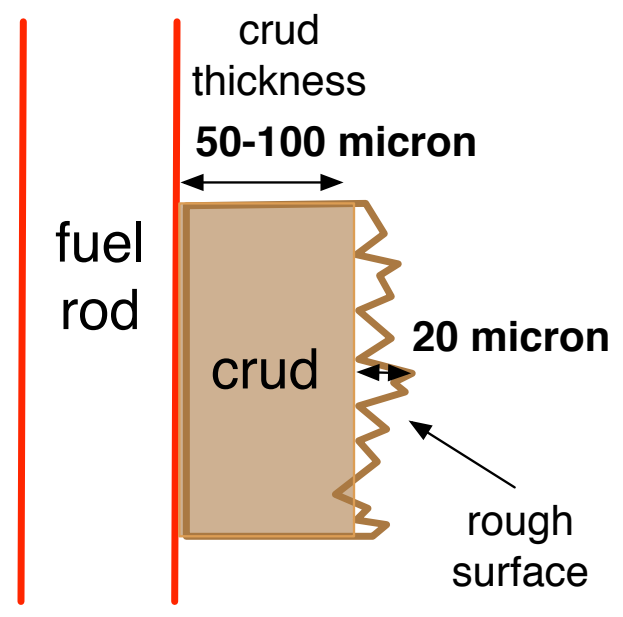

Figure 4: Schematic representation of crud thicknesses

For clarity, it is useful to point out that historically, pioneer experiments on surface roughness have used sand-roughened pipes [15], and this has led this type of roughness to become a reference definition, also known as sand roughness. The sand roughness consists of small spheres packed together on a flat surface, where the diameter of the spheres corresponds to the roughness height. Any random surface can be approximately associated with an equivalent sand grain roughness height, thus reducing the geometrical characterisation to a single parameter. Although both the definitions of geometric roughness height and sand roughness height are accepted and used in the literature, the relation between them remains still rather indeterminate.

\subsubsection{DIMENSIONLESS ROUGHNESS HEIGHT AND ROUGHNESS REGIMES}

It is usually convenient to convert the roughness height into a non-dimensional quantity related to the flow conditions, as:

$$
k_{s}^{+}=\frac{\rho k_{s} u^{*}}{v}
$$

where $\rho$ is the fluid density, $v$ is the fluid viscosity, $k_{s}$ is the geometric roughness height and $u^{*}$ is the friction velocity (defined in the Appendix).

This dimensionless roughness height $k_{s}^{+}$is sometimes referred to as the roughness Reynolds number. It is no longer a function of only the characteristics of the surface but depends also on the flow. Experiments have shown that the nature of the effects of roughness on the velocity profile in proximity of the wall generally depends on the value of $k_{s}^{+}$as follows [16]:

- $k_{s}^{+}<5$ : The roughness is confined in the viscous sub-layer and does not affect the flow characteristics: the surface can be considered hydraulically smooth, Figure 5 .

- The range $5<k_{s}^{+}<50$ is called the transition regime; the roughness elements essentially interact with the buffer layer, where most of the turbulence is created.

- $k_{s}^{+}>50$ : The flow is said to be in the fully rough regime. The surface roughness protrudes through the viscous region, and the effects of roughness (wall 
shear stress increase and consequent near wall axial velocity reduction) become independent of viscosity [17]. This regime corresponds, in Moody's diagram, to the region where the friction factor is no longer dependent on the Reynolds number (horizontal lines).

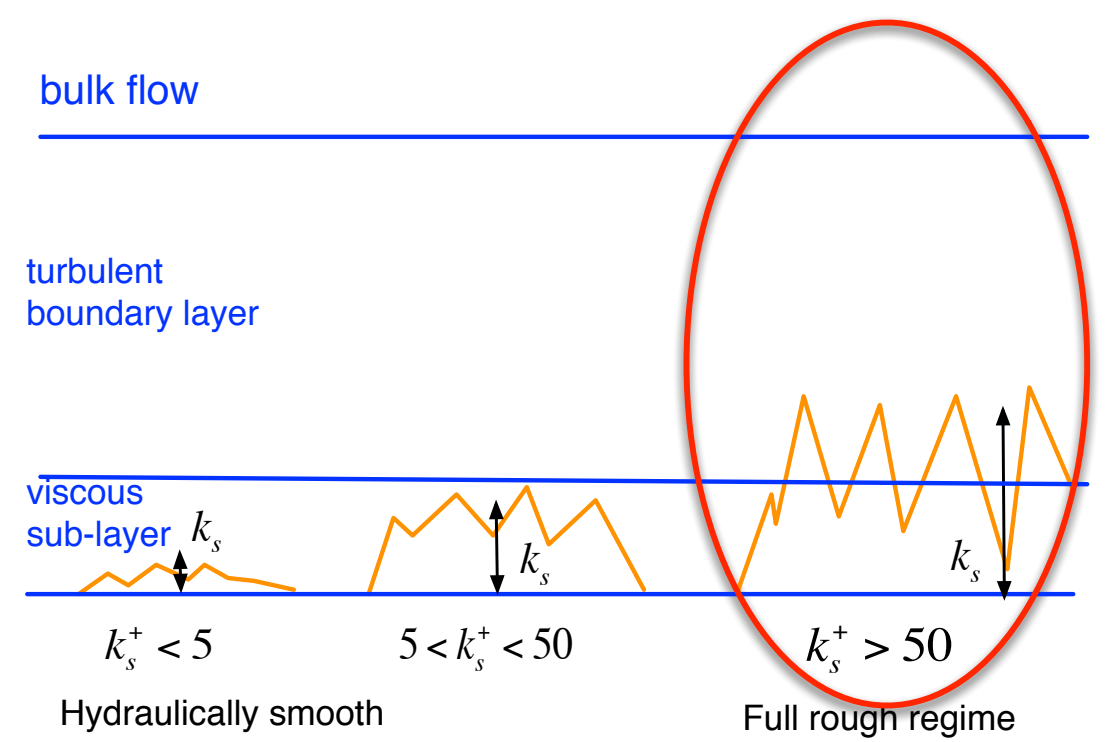

Figure 5: Roughness regimes

It is important to note that this classification is valid if the absolute roughness heights involved are small compared to the total thickness of the boundary layer, such as is the case for the values involved in this study. For the values of roughness heights studied in this paper, up to $\sim 20$ micron, or equivalently for the relative roughness heights (as compared to the equivalent hydraulic diameter of a sub-channel), up to 0.0015 , (see Table 1), the flow can be classified as to be in the fully rough regime. This corresponds to the asperities associated with the roughness being taller than the thickness of the laminar sub-layer, and the wall shear stress becomes less dependent on viscosity.

\subsection{ROD BUNDLE PARAMETERS}

The geometrical and operating parameters adopted for the analysis are typical of a PWR reactor and listed in Table 1 . The definitions of the derived quantities are given in the Appendix.

\begin{tabular}{|c|c|c|}
\hline \multicolumn{3}{|l|}{ Geometrical parameters } \\
\hline Rod diameter & $\mathrm{D}$ & $9.5 \mathrm{~mm}$ \\
\hline \multicolumn{2}{|l|}{ Rod pitch } & $12.6 \mathrm{~mm}$ \\
\hline Roughness height & $k_{s}$ & up to 20 micron \\
\hline \multicolumn{3}{|l|}{ Operating conditions } \\
\hline Sub-channel mass flow rate & $\mathrm{G}$ & $0.3 \mathrm{~kg} / \mathrm{s}$ \\
\hline
\end{tabular}




\begin{tabular}{|c|c|c|}
\hline Channel temperature & $\mathrm{T}$ & $\sim 586 \mathrm{~K}$ \\
\hline Pressure & $\mathrm{P}$ & $15.5 \mathrm{MPa}$ \\
\hline \multicolumn{2}{|l|}{ Peak linear power rate } & $47 \mathrm{~kW} / \mathrm{m}$ \\
\hline \multicolumn{3}{|l|}{ Fluid parameters } \\
\hline Viscosity & $v$ & $8.5941 \cdot 10^{-5} \mathrm{~Pa} \cdot \mathrm{s}$ \\
\hline Density & $\rho$ & $712.53 \mathrm{~kg} / \mathrm{m}^{3}$ \\
\hline \multicolumn{3}{|l|}{ Derived quantities } \\
\hline Sub-channel hydraulic diameter & $\mathrm{D}_{\mathrm{H}}$ & $11.7 \mathrm{~mm}$ \\
\hline Sub-channel flow area & A & $87.8 \mathrm{~mm}^{2}$ \\
\hline Sub-channel mass flux & & $3715 \mathrm{~kg} / \mathrm{m}^{2} . \mathrm{s}$ \\
\hline Relative sub-channel roughness height & $k_{s} / \mathrm{D}_{\mathrm{H}}$ & up to 0.0015 \\
\hline Sub-channel Reynolds number & $\operatorname{Re}$ & $\sim 500,000$ \\
\hline \multicolumn{2}{|l|}{ Turbulent boundary layer thickness } & $\sim 200$ micron \\
\hline Dimensionless wall distance & $\mathrm{y}^{+}$ & 74-104 \\
\hline Dimensionless roughness height & $k_{s}^{+}$ & $40-95$ \\
\hline Prandtl number & $\operatorname{Pr}$ & $\sim 0.95$ \\
\hline \multicolumn{2}{|l|}{ Average axial velocity } & $\sim 5.2 \mathrm{~m} / \mathrm{s}$ \\
\hline \multicolumn{2}{|l|}{ Peak fuel heat flux } & $\sim 1580 \mathrm{~kW} / \mathrm{m}^{2}$ \\
\hline
\end{tabular}

Table 1: Geometrical parameters and operating conditions, typical of a PWR, used in the present paper. The definitions of the derived quantities are specified in the Appendix.

\section{THE METHODOLOGY}

As discussed above, the layer of crud formed on the cladding of a fuel pin can have a thickness of about 50-100 micron. Whilst this thickness reduces the cross sectional flow area of the sub-channel the fractional reduction in flow area is small, and we have neglected it. Focus is rather on the increased flow resistance due to the surface roughness; it is to be expected that this crud surface roughness, where present, will increase frictional resistance to the flow of coolant and consequently reduce the average mass flow rate through the sub-channels with crud-coated rods.

The reduced mass flow rate, relative to a clean uncrudded sub-channel, will reduce the heat transfer coefficient, and increase the local bulk coolant temperature. The reduced flow rate also has a detrimental effect on the Critical Heat Flux (CHF) and on the DNB ratio. The flow chart of the methodology, linking the occurence of crud to an altered DNBR, is illustrated in Figure 6.

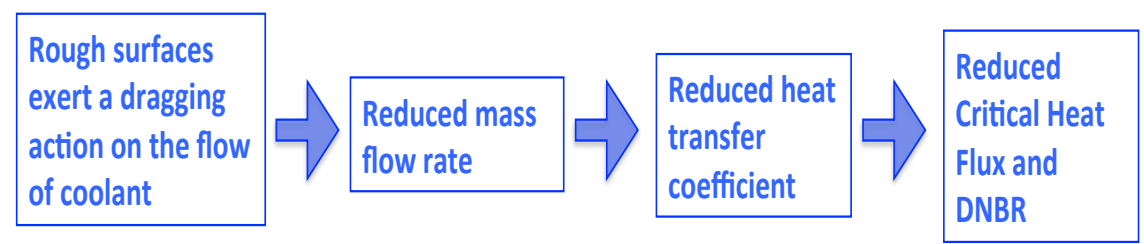


Figure 6: Phenomenological flow-chart of the effects of crud on CHF and DNB ratio

The computational analysis follows the steps in Figure 6. The mass flow rate in the various sub-channels (crudded and uncrudded) is firstly obtained by using a CFD model, then the heat transfer coefficient is evaluated, by post processing the CFD results and, finally, the effects on the critical heat flux and DNBR are evaluated by applying empirical correlations. These steps are described in detail, in the same order, in Sections 4 and 5.

\section{MASS FLOW RATE AND TEMPERATURE ANALYSIS}

The localized effects require a detailed calculation of the thermal-hydraulic physics occurring in the proximity of the rods and within the sub-channels. It is thus necessary to deploy full CFD tools to evaluate the detailed distributions of coolant flow and mass flow rate along each single channel. In this paper we report the results of our attempt to predict the flows using the STAR-CCM+ CFD code. STAR-CCM+ adopts the definition of sand grain equivalent roughness to describe the height of the roughness [18], but we use the geometric roughness height instead, irrespectively.

Since the roughness heights are an order of magnitude smaller than the boundary layer, it is not necessary to model them as geometrical features and, therefore, there is no need to resolve them numerically, which plainly would be impractical. A steady RANS approach is adopted instead. In RANS simulations the boundary layer is not resolved numerically, but the velocity profile is approximated with some pre-defined wall functions, based on empirical experience, [17, 19]. Within the steady RANS model, turbulences have been computed by applying the realizable K-epsilon method, based on the Boussinesq eddy viscosity approximation. Details of the computational model are described in the following subsections.

\subsection{COMPUTATIONAL DOMAIN}

As with any CFD calculation, the selection of the domain for analysis, and the refinement of the mesh within that domain, represent a pragmatic compromise between the requirements of fidelity, and the need to keep computational costs tolerable. In this study, to contain the computational costs, the analysis has been limited to a bundle with a small number of rods and sub-channels, Figure 7 , and a symmetric sector has been thus considered instead of the entire fuel assembly. This domain approximation is customary in typical PWR sub-channel analyses.

Figure 8 illustrates the cross section of the bundle analysed. The top three rows of rods (coloured red) are covered with crud, whilst the remaining rods are clean. Two sub-channels are considered as most relevant for the analysis of the results, namely sub-channel $A$, as being surrounded by crudded rods, and thus most affected by the crud, and sub-channel B, as being clean and the least affected by crud. Symmetric boundary conditions are applied all along the external perimeter of the domain analysed. 


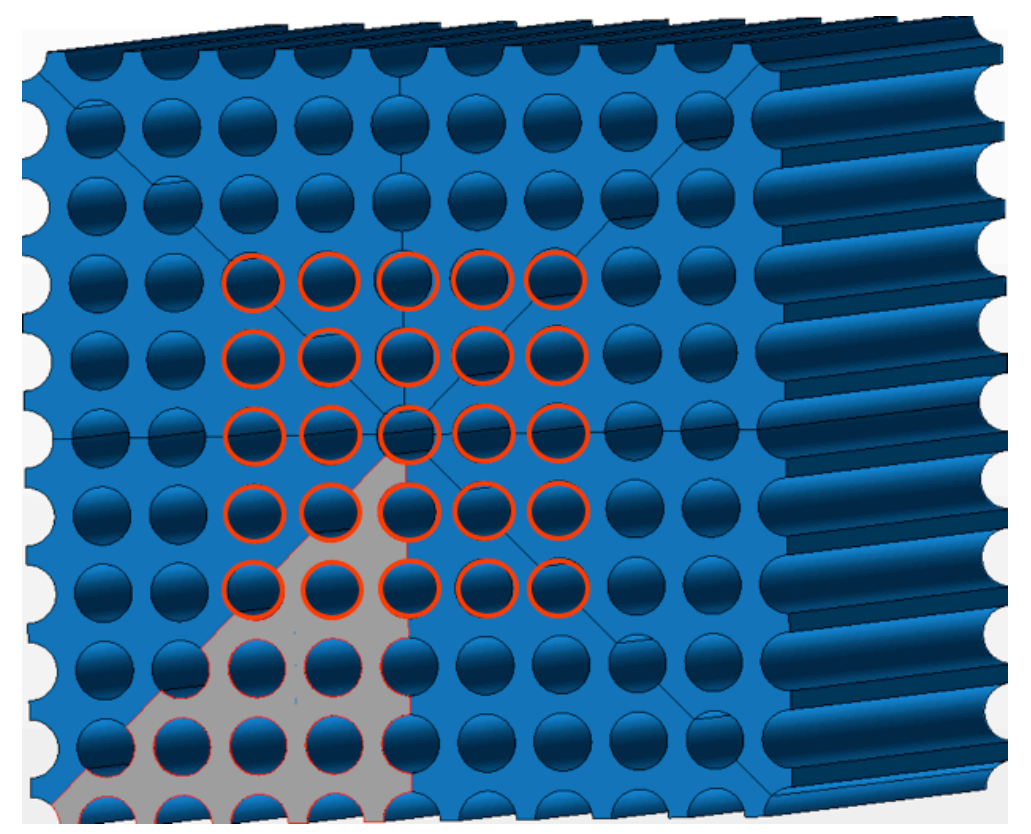

Figure 7: Cluster of crudded rods (in red) within a core sub-channel, and the computational domain selected (in grey).

Since in a PWR the presence of crud is generally limited to the top half of the rods (approximately the region between $60 \%$ and $80 \%$ of the rod length from inlet) it is not necessary to model the entire length of the bundle: the computational domain can be restricted to the top half. In order to do so, a preliminary computation, using a relatively coarse mesh, was performed for the entire length of the bundle, without any crudded rods. The fully developed flow field part way along the rod bundle so predicted has then been used in subsequent simulations as the input flow to a shorter domain, which then could properly begin only a fairly short distance upstream of the crudded region. This is indicated in Figure 9. The mesh grid for the shorter domain was refined in both the cross sectional and axial directions. The fully developed field obtained from the coarser mesh was interpolated at the inlet of the shorter domain to match the nodes of its finer mesh.

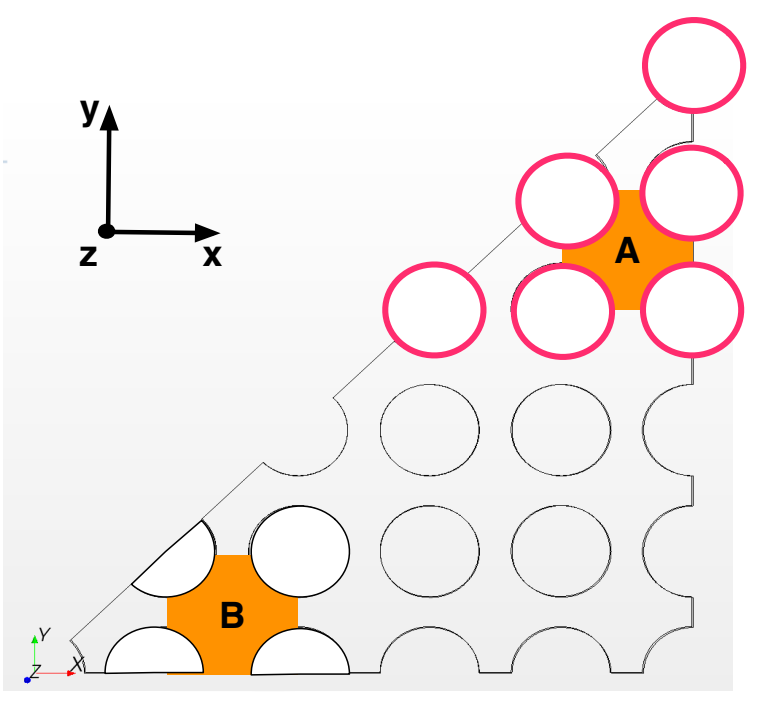


Figure 8: Cross section of the symmetry sector of the rod bundle analysed. Rods in the top three rows (coloured red) are crudded, whilst all the other rods are clean. Sub-channel A constitutes a crudded channel, whilst sub-channel B is a clean one.

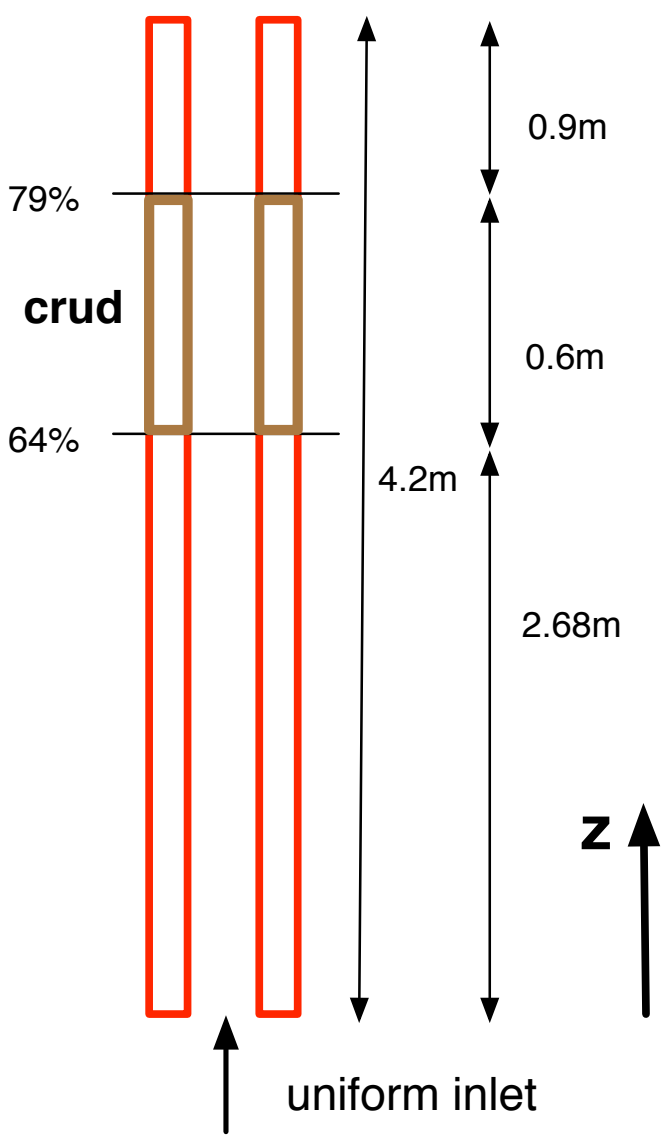

(a)
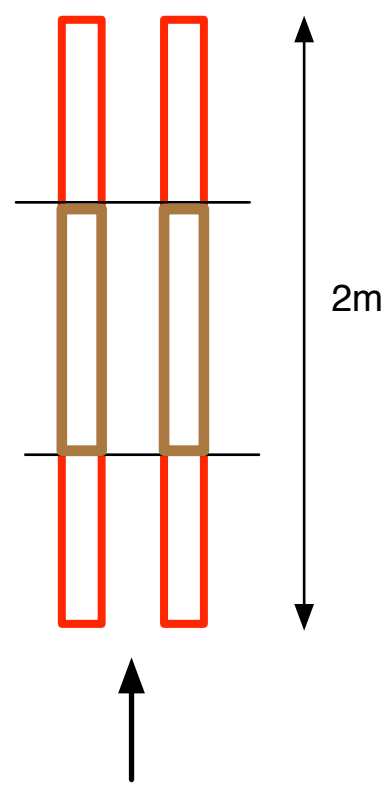

fully developed inlet

Figure 9: (a) The computational domain used to obtain the fully developed flow conditions and (b) the shortened computational domain used to analyse the crudded regions

\subsection{NEAR WALL MODELLING}

The velocity profile passes from purely viscous very near the wall, i.e. in the viscous sub-layer, to turbulent. The wall functions, used to solve the flow near the walls, constitute effectively a set of mathematical relations used to obtain artificial boundary conditions for the continuum equations. Typical wall functions in CFD are the blended linear-log laws $[16,18]$. With this approximation, the region near the wall is subdivided into three regions, namely:

(1) The viscous sub-layer, extending from the surface of the wall to a distance of $y+\sim$ 5 , over which region the mean velocity profile is taken to be linear.

(2) The log-law region, extending from $y+\sim 30$ to $y+\sim 100$, where the mean velocity profile is modelled as logarithmic, (Eq. 2),

(3) Between these two regions, the buffer region, where the transition of the mean velocity from linear to log-law is smoothed out by a blending function. 
$\left\{\begin{array}{cc}u^{+}=y^{+} & y^{+}<5 \\ u^{+}=\frac{1}{k} \ln \left(E y^{+}\right) & 30<y^{+}<100\end{array}\right.$

Eq. 2

$u^{+}$is the dimensionless flow stream mean velocity normalized with respect to the friction velocity $u^{+}=u / u^{*} .\left(u^{*}\right.$ is defined in the Appendix).

Typical values of $k$ and $E$ are 0.42 and 9 , respectively. Within the intermediate buffer region, $5<y^{+}<30$, the velocity profile is a blend of the two wall functions.

In the presence of rough surfaces the log-law approximation is still employed, but the velocity profile is reduced by a constant factor depending on the roughness height. Thus the effect of the roughness is accounted for by introducing a correction factor into the log-law formulation [18], as expressed in Eq. 3.

$u^{+}=\frac{1}{k} \ln \left(E y^{+}\right)-\Delta u^{+}\left(k_{s}^{+}\right)$

Eq. 3

where the values of $E$ and $k$ are unchanged and the velocity shift $\Delta u^{+}$is a function of the roughness height $k_{s}^{+}$. Eq. 3 can also be rewritten in the compact format:

$u^{+}=\frac{1}{k} \ln \left(\frac{E}{f} y^{+}\right)$

Eq. 4

where $f$ is the roughness function and is related to the velocity shift as $\Delta u^{+}=\frac{1}{k} \ln (f)$.

For the range of roughness heights used in this paper, i.e. $k_{s}^{+}>50$ (fully rough regime), the roughness function $f$ is computed as:

$f=B+C k_{s}^{+}$

Eq. 5

with typical values: $B=0$ and $C=0.253$. For convenience, the near wall velocity is plotted in Figure 10 as a function of the roughness height. 


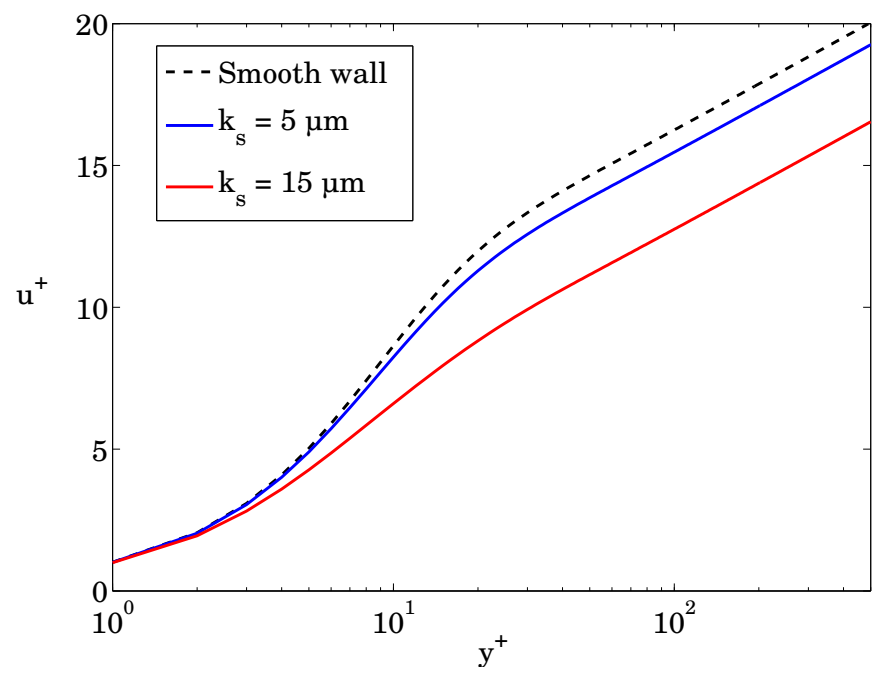

Figure 10: Blended wall functions used to define the flow stream velocity in proximity of the walls

Just as for the mass and momentum conservation equations, the energy equation is not solved numerically adjacent to the walls. The temperature profile near the rods is prescribed by wall functions too. Since the Prandtl number is approximately unity for the fluid and flow parameters defined in Table 1, i.e. there is a balance between the momentum and thermal diffusivity, it is a valid assumption to consider the thermal sub-layer to be equivalent in size to the viscous sub-layer. With this approximation it is possible to prescribe the profile of temperature in a similar manner to the flow velocity, i.e.:

$\left\{\begin{array}{c}t^{+}=\sigma y^{+} \quad y^{+}<10 \\ t^{+}=\sigma_{t}\left[\frac{1}{k} \ln E y^{+}+P\left(\sigma, \sigma_{t}\right)\right] y^{+}>10\end{array}\right.$

Eq. 6

where $\sigma$ is the molecular Prandtl number and $\sigma_{t}$ is the turbulent Prandtl number, defined in the Appendix. Much as for the velocity, the temperature is expressed in dimensionless form $t^{+}$as:

$t^{+}=\left(T-T_{\text {wall }}\right) \frac{\rho C_{p} u^{*}}{q^{\prime \prime} \text { wall }}$

where $T_{\text {wall }}$ and $q^{\prime \prime}{ }_{\text {wall }}$ are the temperature at the wall and the amount of heat flowing across the rods into the fluid, respectively. The value of $T_{\text {wall }}$ is unknown, but prescribed by Eq. 6 and dependent of the applied rod heat flux $q^{\prime \prime}{ }_{\text {wall }}$.

\subsection{MESH}

Various types of volume mesh are available within STAR-CCM+, including trimmed, tetrahedral and polyhedral [18]. From these, trimmed cells were selected, as the geometry is mainly uniform in the longitudinal direction, and numerical diffusion is minimized when the flow is aligned with the mesh. 
To improve the accuracy of the numerical solution near the domain walls, a prismatic near-wall layer was introduced, as this provide facilities to control the progression of the thickness for the cells near the walls. The number and height of the prismatic cells, with respect to the wall, depend on the degree of turbulence (i.e. the Reynolds number of the flow) and the thickness of the turbulent boundary layer. The typical Reynolds number for the bundle modeled in this exercise is $\sim 500,000$, and the boundary layer thickness is of the order of a few hundred microns (this thickness is equivalent to a dimensionless wall distance $y^{+} \sim 200$, and has been obtained by considering sub-channels like a pipe equivalent with a hydraulic diameter of 11.7 $\mathrm{mm})$.

With these parameters the thickness of the prism layer has been set to twice the boundary layer thickness, i.e. about 200 micron, allowing a relatively coarse mesh ( $3 \times 10^{6}$ degrees of freedom) to be used whist still retaining good fidelity; see Figure 11.

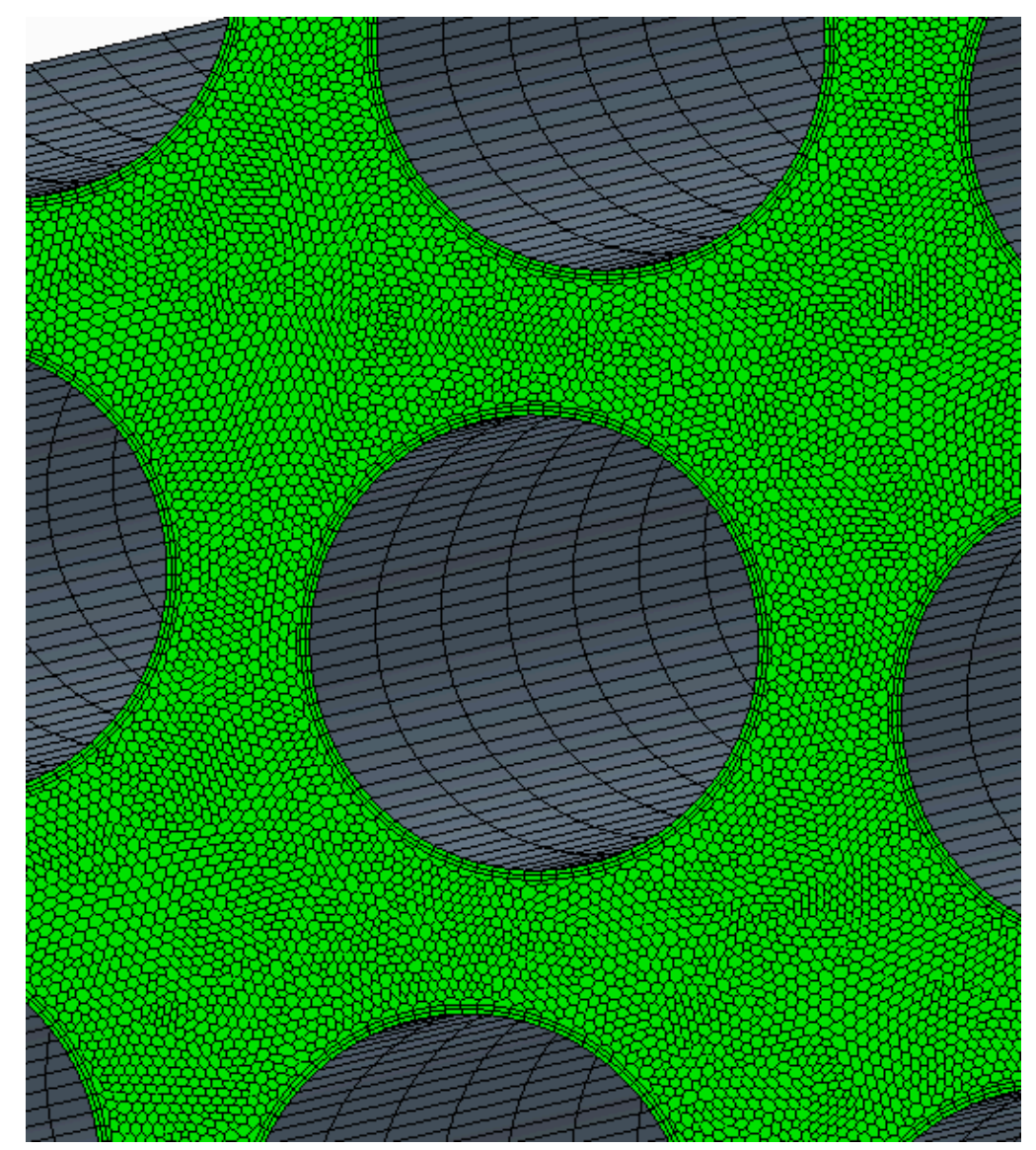

Figure 11: Details of the mesh. Orthogonal prismatic cells are used near the metal walls.

The necessary refinement of the mesh near the walls and the choice of the type of wall treatment applied depend on the thickness and other characteristics of the boundary layer, and on the local turbulence [17]. For the turbulent flow regime of the case studied in this paper, the two most appropriate approaches are the high $\mathrm{y}+$ and the two-layer all $y+$ wall treatments [20]. Both these two treatments assume that the near-wall cell lies within the boundary layer, i.e. within the log-law region, and are suitable for the type of flow involved. 


\section{HEAT TRANSFER COEFFICIENT AND CRITICAL HEAT FLUX ANALYSIS}

The heat transfer coefficient is evaluated by post processing the temperature distributions obtained from the CFD computations.

For each rod and each axial location, the averaged fluid temperature across a reduced cross-section of the CFD model that is representative of a sub-channel, is calculated. These values represent the bulk fluid temperature, $T_{b u l k}$, surrounding each rod. Using this bulk temperature, the values of the rod surface temperature, $T_{\text {wall }}$, directly computed from the CFD, and the rod heat flux, $q{ }^{\prime \prime}$ wall , it is possible to estimate the local values of the heat transfer coefficient as [21]:

$$
h=\frac{q^{\prime \prime}{ }_{\text {wall }}}{\left(T_{\text {wall }}-T_{\text {bulk }}\right)}
$$

The results calculated by this approach have been compared with those obtained by applying more general empirical correlations. More specifically, in locations without crud the computed results have been compared against the Dittus-Boelter correlation [21], while for crudded regions the Dipprey-Sabersky correlation [21], valid for pipes with rough surfaces, has been used for comparison. The computed results were in good agreement with the values obtained from the correlations.

Since all the parameters necessary to calculate the heat transfer coefficient, as described in Eq. 8, were directly available from the simulation, the use of the CFD results has been adopted, rather than the use of correlations. This choice was also reinforced by the fact that correlations are generally accurate enough only under rather specific circumstances (i.e. single pipe, smooth wall, etc.)

The critical heat flux has been calculated locally by applying the Westinghouse- 3 (Tong) correlation, as widely accepted and representative of typical PWR reactors. For completeness Tong's correlation is reported in the Appendix. Although a nonuniform heat flux (of the shape typical of PWR reactors) has been applied to the rods as for the generation of heat in the channels, in applying the W3 correlation such effect has been neglected for simplicity. The correction factor $F$, to account for nonuniform heat fluxes, was computed to be near unity, but also we are anyway seeking to identify changes in DNBR occasioned by the crud, further reducing its importance. The local quality, $x_{e}$, dependent of the local enthalpy, has been calculated as [21]:

$x_{e}=\frac{C_{p}\left(T_{\text {wall }}-T_{b u l k}\right)}{h_{f z}}$

Eq. 9

where $h_{f g}$ is the specific enthalpy of evaporation.

It is useful to notice that, although the local average quality is practically zero, and thus negligible in the W3 correlation at the point of critical heat flux, it is non negligible (and with negative sign) in the bottom part of the bundle where the coolant is in a sub-cooled regime.

The ratio between the local heat flux and the CHF, the DNB ratio (DNBR), is defined as the ratio of the critical heat flux at a specific location and the operating heat flux at that location. The procedure applied to compute the DNBR is reported for completeness in the Appendix. 


\section{RESULTS}

Following the pattern highlighted in Section 3, the results presented in this section are grouped by following the order of the methodology. The relevant physical parameters defining the operational conditions are those summarised in Table 1.

\subsection{VELOCITY PROFILES}

The most obvious parameter affected by the increased frictional force exerted by the roughnesses on the flow is the axial velocity, which in turn has a direct effect on the mass flow rate. It is therefore important to focus first on the results of the axial velocity.

The fully developed velocity profile, before reaching the crudded region of the bundle, has the same cross sectional distribution in each of the sub-channels computed. A contour plot of the axial velocity upstream of the crudded region is shown in Figure 12a. As the coolant passes through the crudded region, the flow is decelerated in the sub-channels surrounded by crudded rods and diverted towards the clean sub-channels, as evident in Figure $12 \mathrm{~b}$, in order to ensure the overall continuity of the mass flux.

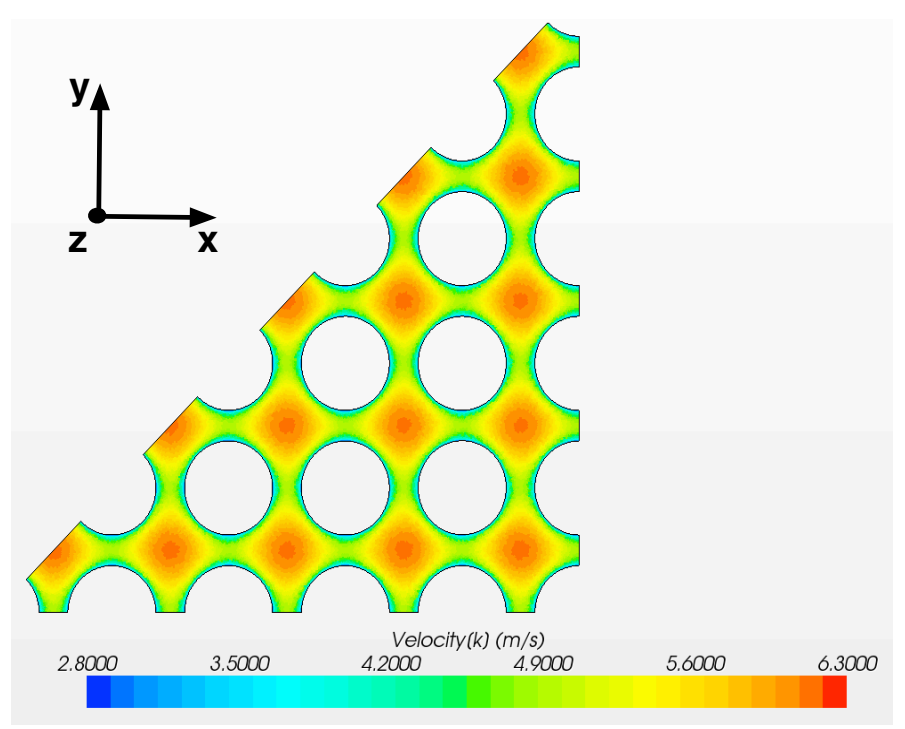

(a) 


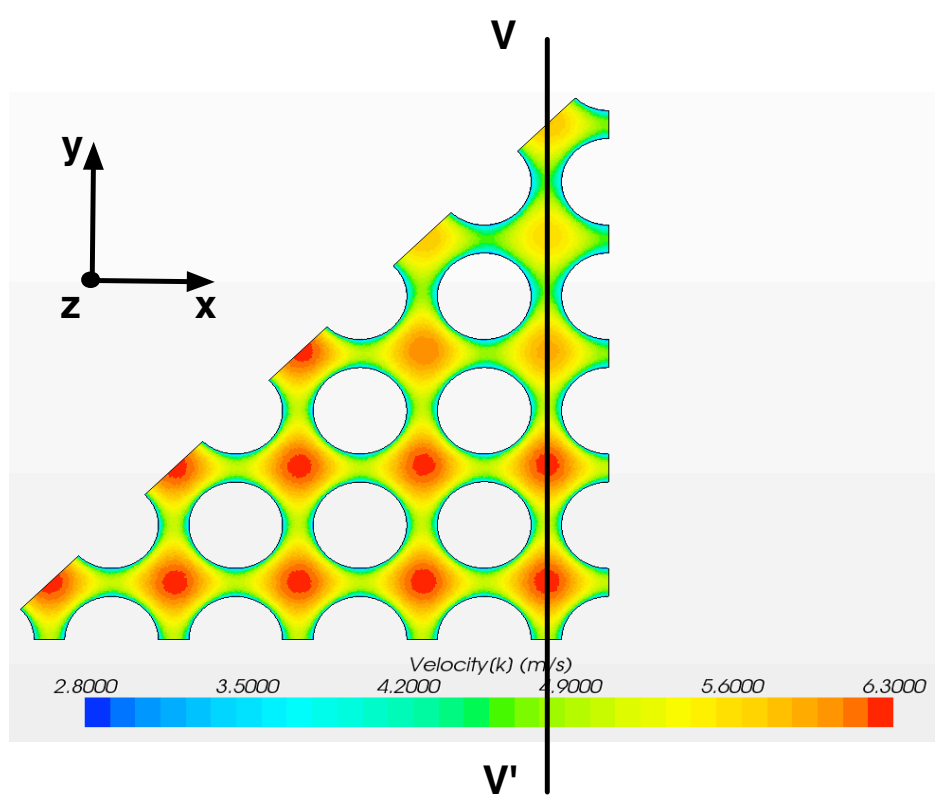

(b)

Figure 12: Axial velocity distribution at cross sectional areas: (a) upstream of the crudded region; (b) immediately downstream of the crudded region. The inlet axial velocity is $5.2 \mathrm{~m} / \mathrm{s}$. The crud roughness height is 10 micron

For a quantitative evaluation of the axial velocity a line section along the centers of the sub-channels, $V-V$ ' in Figure 12b, is taken and re-plotted in Figure 13. The axial location at which this velocity profile is plotted is at the point where the crudded region ends. There is a clear decrease in the axial velocity, due to the additional flow resistance of the cud. This effect becomes stronger as the rougheness height increases. Since the flow redirected towards the clean sub-channels can redistribute itself amongst (in our model) a larger number of clean sub-channels as compared to the number of crudded ones, the effect on the axial velocity profile in the clean channels is modest. 


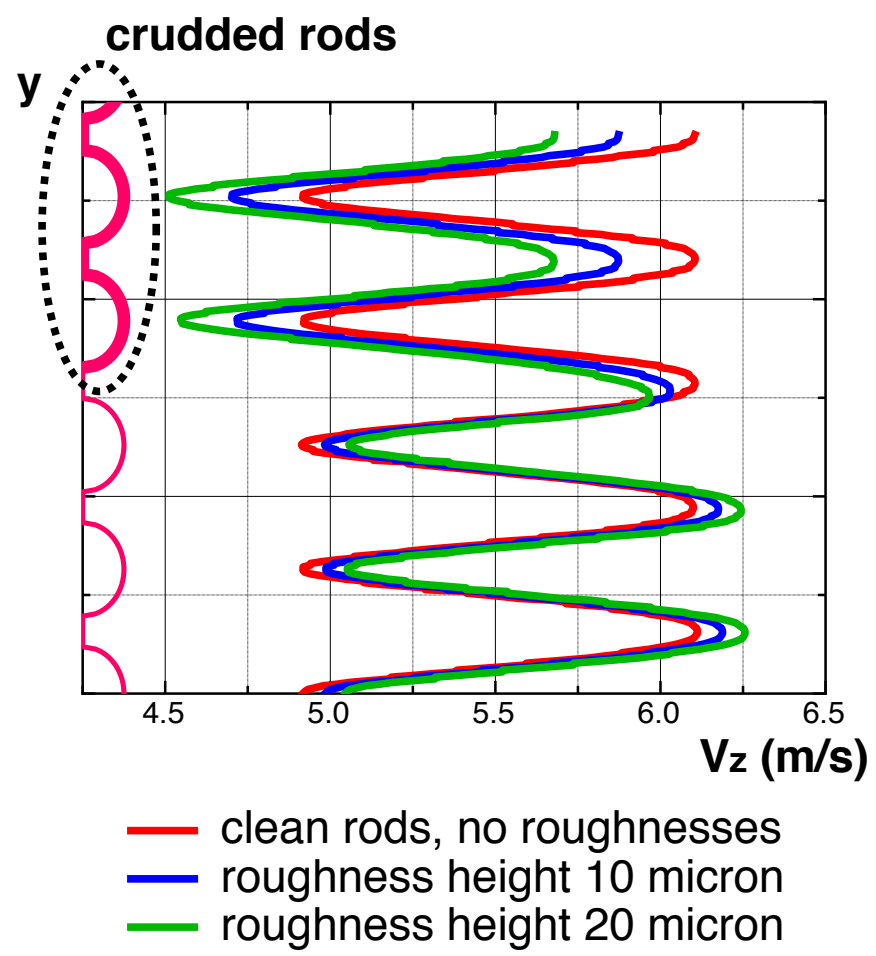

Figure 13: Axial velocity (in $\mathrm{m} / \mathrm{s}$ ) taken at the line section $\mathrm{V}-\mathrm{V}^{\prime}$ ' in Figure $12 \mathrm{~b}$.

Beside the velocity, other hydraulic parameters, such as wall shear stress and channel pressure drop, are directly influenced by the presence of the crud. The computed results for these behave as expected, but plots are omitted here for brevity.

\subsection{MASS FLOW RATE REDUCTION}

To assess the mass flow rate reduction as the coolant flows along the longitudinal direction and through the crudded region, it is useful to observe the axial variation of the axial velocity, taken at the center of the sub-channels. This is plotted in Figure 14 for sub-channels A (crudded) and B (clean), as defined in Figure 8. Upstream of the crudded region the velocity is the same within all the sub-channels, and the same as for a fully-clean bundle. As the coolant encounters the crud the flow diversion begins, with a net velocity decrease in the crudded sub-channel (A). Downstream of the crudded region, although the flow tends to recover towards uniformity after a long distance, the reduced flow still persists for many hydraulic diameters. 


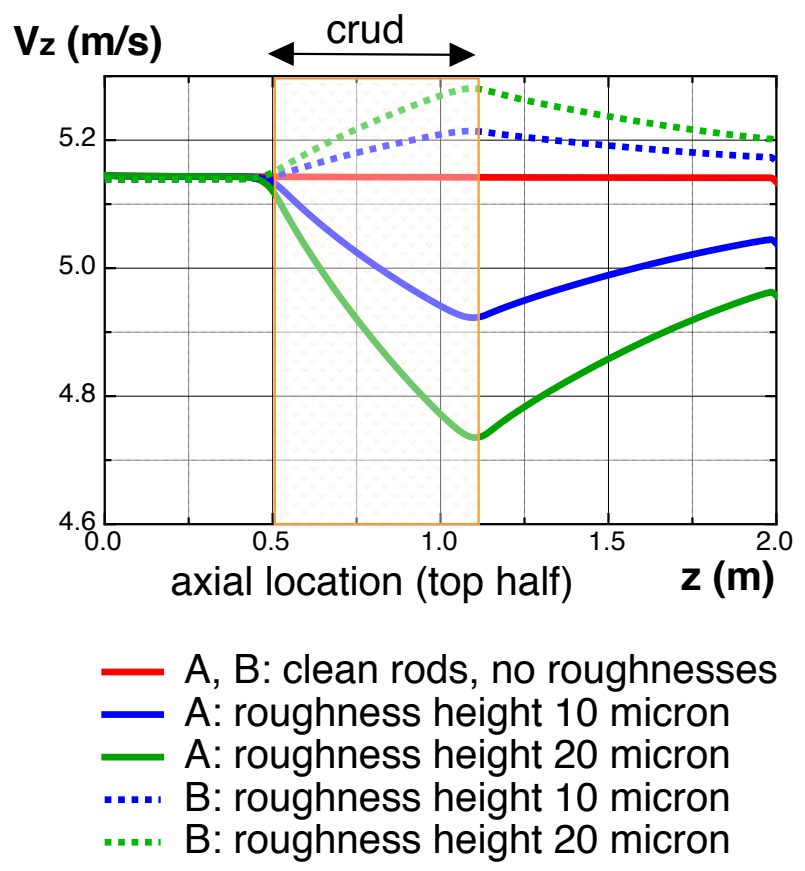

Figure 14: Axial velocity versus longitudinal position, taken at the center of the two sub-channels, A (crudded) and B (clean), as defined in Figure 8. The shaded window indicates the crudded region. The plot is limited to the computational domain, and is for the top half of the bundle only.

Evaluating the average axial velocity at a cross section just downstream of the crudded region, it is possible to determine the mass flow rate within each subchannel. By comparing such values for crudded rods against the case of clean bundles, it is possible to estimate the percentage reduction of mass flow rate as a function of crud roughness height. These results are shown in Figure 15: realistic values of roughness height, up to $\sim 20$ microns, can lead up to a $\sim 10 \%$ reduction in mass flow rate within sub-channels suffering crud deposition.

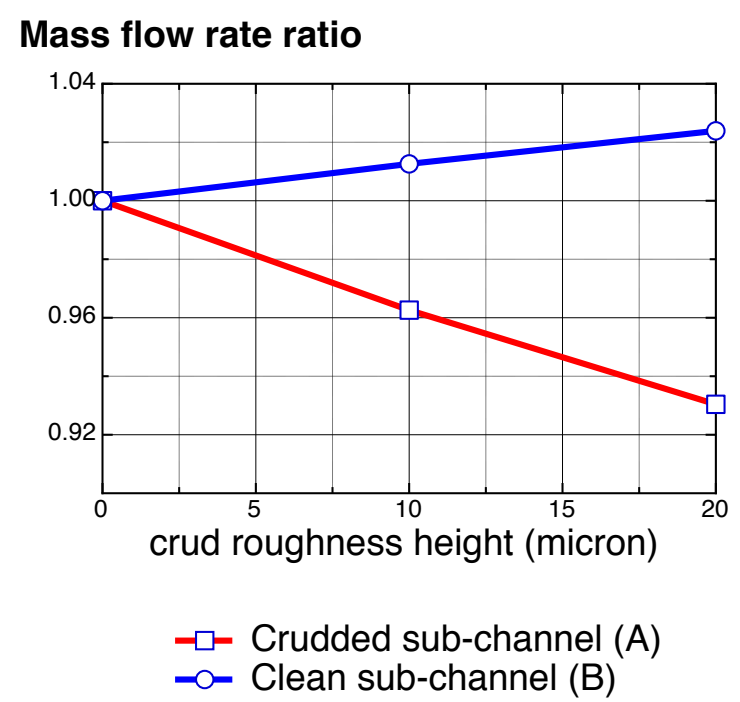

Figure 15: Percentage of mass flow rate change as a function of crud roughness height. 


\subsection{SURFACE TEMPERATURE}

The computed temperatures at the surface of the rods are plotted in Figure 16, (the axial variation of the heat flux generated by the fuel pins is also plotted for reference). The Temperature profile follows broadly the profile of the pin heat flux. Two regions are of major interest: the crudded region, where there is a decrease in temperature due to the presence of roughness, and the region downstream of the crud, where the reduced mass flow rate leads to an increase of temperature. The reduced surface temperature within the crudded region is due to locally increased turbulence. The roughnesses of the crud surface generate more mixing of the flow, which in turn increases the effectiveness of heat extraction. This is clearer if we observe the turbulent kinetic energy near the rods, as depicted in Figure 17, for the case of crud roughness height of 10 micron. Upstream of the crudded region, the turbulence intensity is the same, and almost constant, for both the crudded and the clean subchannels, $(A)$ and $(B)$, respectively. However, a very marked increase is observed in the turbulence in the crudded sub-channel once the crudded region is reached.

Arising from the crud deposit there are plainly two competing effects at work. There is a (fairly modest) reduction in the mass flow rate, which would tend to reduce the heat transfer coefficient, and an increase of turbulence, because of the surface roughness, which would increase the heat transfer coefficient. This is consistent with the suggestion of Buongiorno [1], arising from his study of crud at a microscopic level.

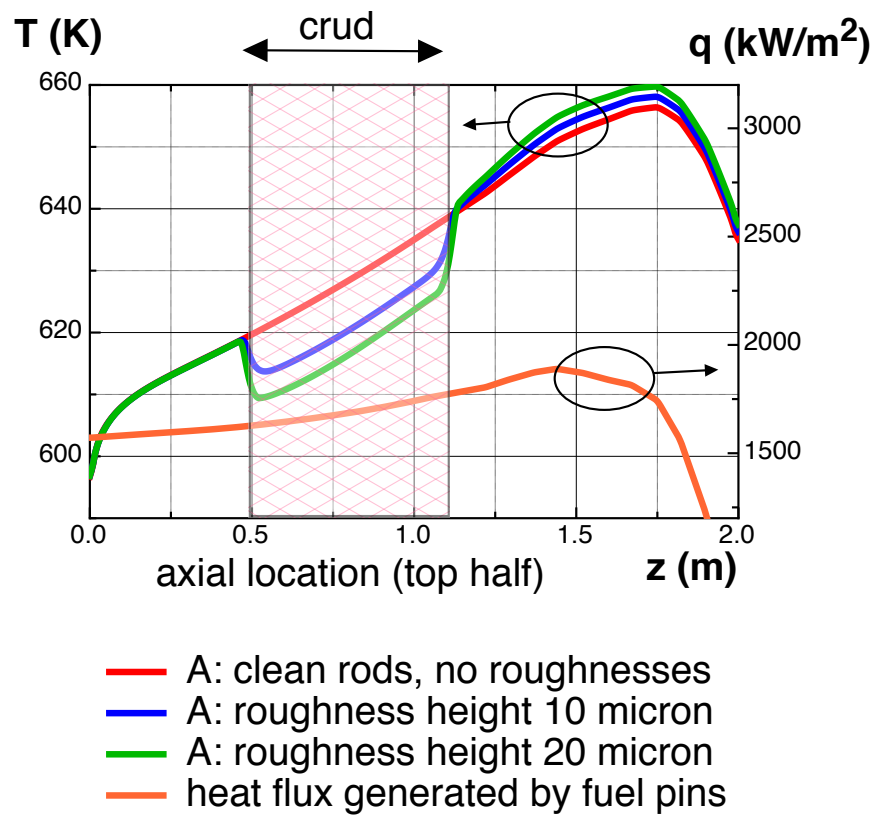

Figure 16: Crud surface temperature (in K), versus longitudinal position. Plots are for a crudded sub-channel, as defined in Figure 8. 


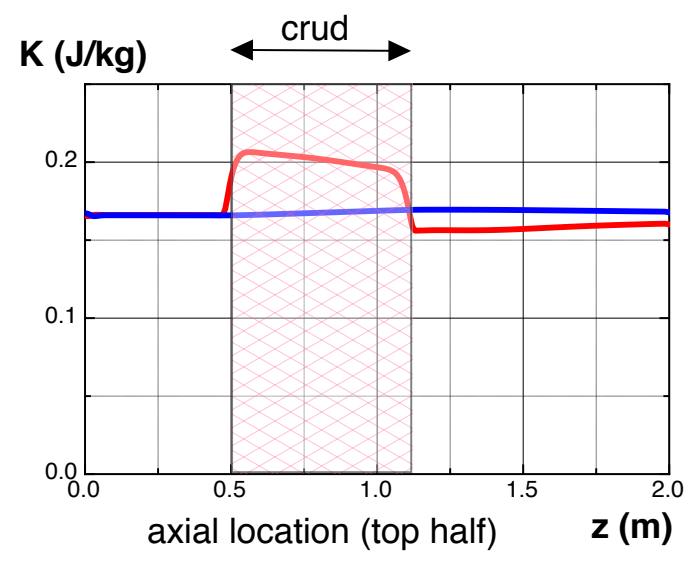

- A: crudded channel

- B: clean channel

Figure 17: Turbulent kinetic energy versus longitudinal position in proximity of the rods wall. The crud roughness height is 10 micron.

\subsection{HEAT TRANSFER COEFFICIENT}

The heat transfer coefficient distribution, calculated as defined in Eq. 8 is plotted in Figure 18. As suggested above, the net effect in the crudded region is that the increased turbulence due to the surface roughness more than outweighs the reduced mass flow rate, and the heat transfer coefficient is increased significantly. Conversely, downstream of the crud deposition the reduced mass flow rate causes a local deterioration of the heat transfer coefficient. However, this localized reduction in heat transfer coefficient seems fairly modest, and results in a negligible increase in clad temperature.
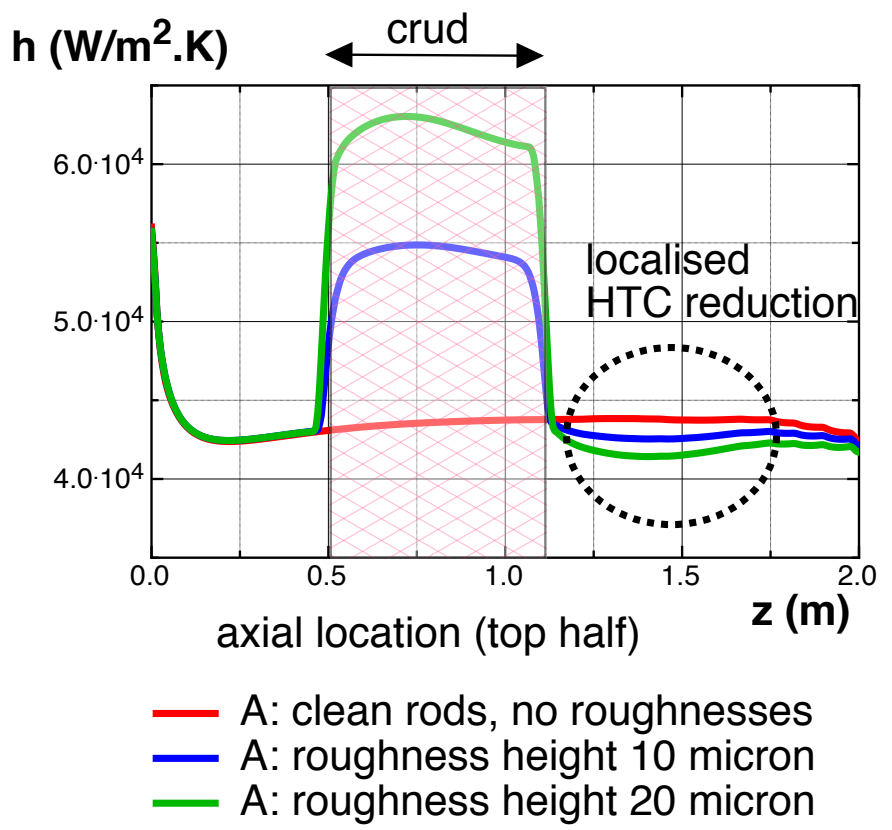

Figure 18: Heat transfer coefficient (in $\mathrm{W} / \mathrm{m}^{2} . \mathrm{K}$ ), versus longitudinal position. Plots are for a crudded sub-channel, as defined in Figure 8.

To assess the accuracy of the computed heat transfer coefficient, results are compared against typical HTC correlations. Specifically, the HTC for uncrudded 
regions is compared against the Dittus-Boelter correlation, valid for flat surfaces; while for the HTC in correspondence of crudded parts of the rods the DippreySabersky correlation, valid for rough surfaces, is used instead. The slight discrepancy occurring downstream of the crud region is due mainly to the fact that the Dittus-Boelter correlation is not strictly valid here, even though the surface is smooth, since the flow is coming out fully altered from the crud region and has not developed yet. These comparisons are visualized in Figure 19. There is a good agreement between the computed values and those obtained from correlations, thus validating the methodology. Whilst the correlations are valid only within limited geometrical and operating conditions, the computational analysis retains its generality and can be applied to a larger variety of cases.

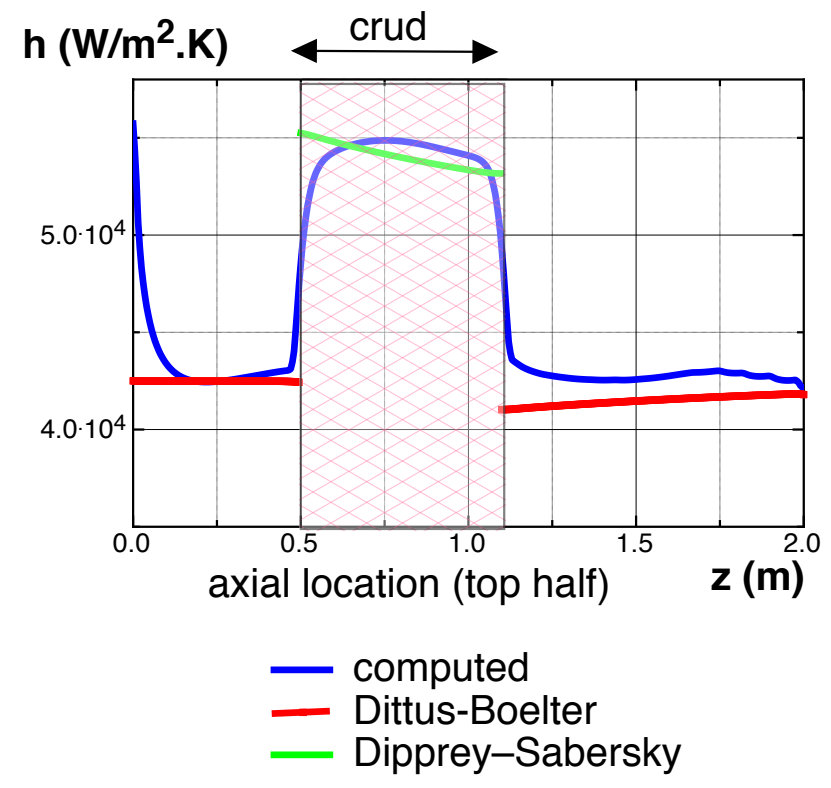

Figure 19: Comparison of computed Heat Transfer Coefficient (in $\mathrm{W} / \mathrm{m}^{2} . \mathrm{K}$ ), vs HTC estimated by physical correlations. Results are for a crud height of 10 micron.

\subsection{CRITICAL HEAT FLUX AND DNBR}

The critical heat flux, computed as detailed in the Appendix, is plotted in Figure 20, along with the axial variation of the applied heat flux. For the specific example examined in this paper it seems that the influence of crud on the CHF is minimal, in a context where typically actual and critical heat fluxes by design differ by perhaps of order a factor of two. Similar conclusions can be drawn when plotting the DNB ratio, in Figure 21. (Note that it is the modificaion in DNBR that is of prime importance; the absolute value is natually a function of the parameters adopted in our study.) 


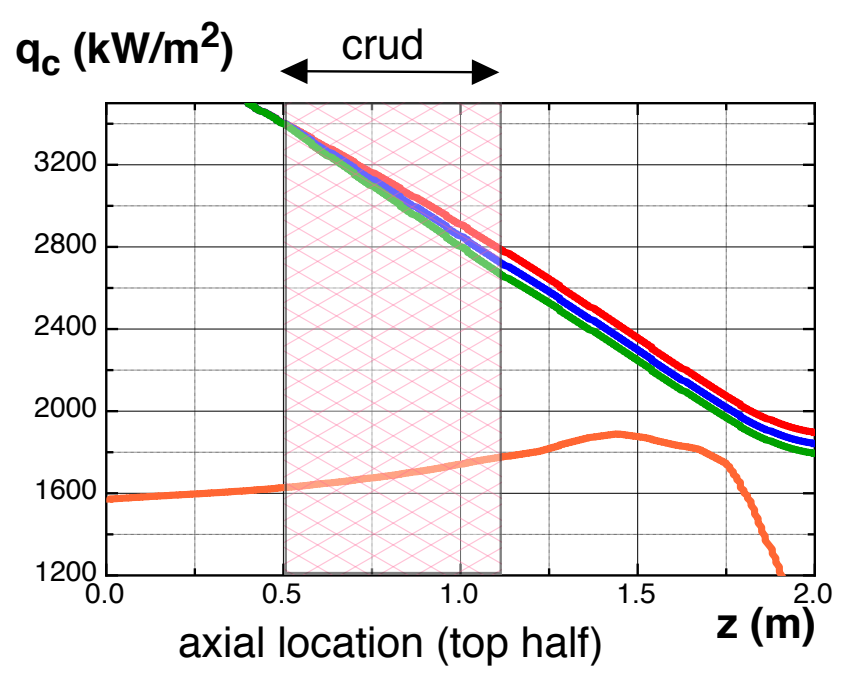

A: clean rods, no roughnesses

A: roughness height 10 micron

A: roughness height 20 micron

heat flux generated by fuel pins

Figure 20: Critical heat flux (in $\mathrm{W} / \mathrm{m}^{2}$ ), versus longitudinal position. Plots are for a crudded sub-channel, as defined in Figure 8 . Also plotted (orange line) is the heat flux generated by the fuel pins.

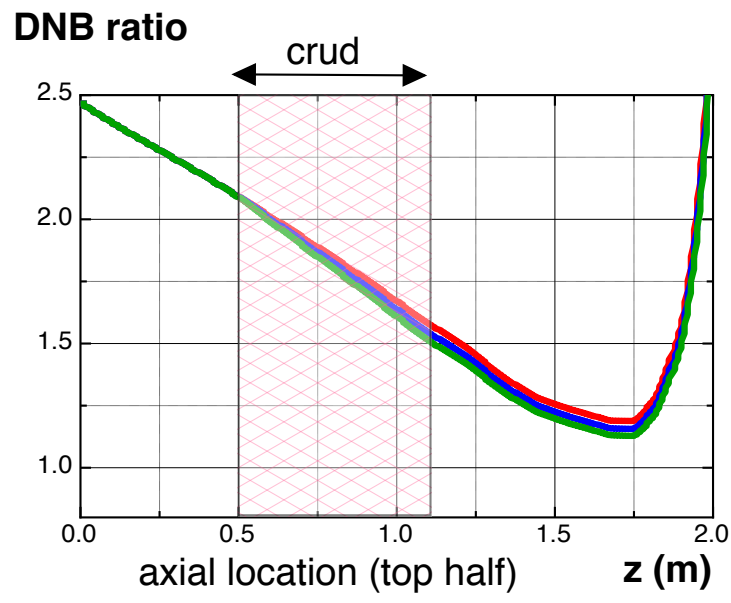

- A: clean rods, no roughnesses

- A: roughness height 10 micron

- A: roughness height 20 micron

Figure 21: Departure from nucleate boiling ratio, versus longitudinal position. Plots are for a crudded sub-channel, as defined in Figure 8.

\subsection{LIMITS OF THE PRESENT ANALYSIS}

The study of crud and crud effects constitutes a complex and interdisciplinary activity, with problems being tackled from different perspectives, by invoking different physics. The common agreed general conclusion is that crud could have an impact on the safety of a LWR, although how and how much still remain debatable and 
unanswered. Because of the high complexity it is difficult to study crud from first principle, with a single and global approach, without relying on some physical approximations. Therefore some limits to the present analysis were inevitable and reported here for clarity.

1. The use of wall functions to prescribe the values of velocity and temperature in proximity of the wall may introduce a factor of uncertainty. Even though the friction factor has been considered to account for the rough surfaces, this approximation relies on the fact that roughness is uniform over the crudded surface. This is plainly not true, as real rough surfaces are highly irregular. Friction velocity should be computed as a local effect of roughness edges. A proper treatment would require to compute Navier-Stokes' equation from first principle, through a Direct Numerical Simulation analysis and resolve the flow velocities at each edge and valley of the irregular rough surface.

2. The cross sectional area reduction due to the crud thickness has not been taken into account: crudded and uncrudded channels were treated with the same cross sectional area.

3. Spacer / mixing grids, present within the core of a real reactor, have not been included in the computational domain. This choice was deliberate, as the focus was primarily on the reduced mass flow rate due to rough surfaces. The mixing grid, itself a source of additional pressure drop over all sub-channels, would be expected if anything to reduce the effects of crud, making this analysis too conservative in that regard.

\section{CONCLUSIONS}

This paper has used CFD calculations to assess the effects of crud deposition on just a subset of the fuel rods in a sub-assembly on sub-channel mass flow rates, on the fuel surface temperatures, and on the critical heat flux. The methodology focuses on effect of the crud on the coolant flow. An example for a typical PWR case has been computed and analysed in detail.

The crud seems to induce two competing effects. There is a modest but noticeable reduction in the mass flow rate in the crudded channel. However, so far as singlephase convection goes, the more important effect is that the crud, which roughens the surface, induces increased local turbulence. This increases the local heat transfer coefficient, and the combined effect of these two competing effects is that the fuel surface temperature is actually reduced by the crud. (Note, however, that we are here talking about the temperature of the outer surface of the crud. Whether any reduction in crud surface temperature is sufficient to outweigh any temperature difference within the crud, between the cladding surface and the crud surface, is a matter that depends on within-crud heat transfer [22]. Heat transfer mechanisms within the crud itself are still something of a topic for research, and incorporation of this into the above analysis is a subject for further study.)

We therefore conclude that modest flow reductions and diversions by clusters of crud coated fuel rods will be unlikely to worsen their thermal hydraulic conditions.

Acknowledgments: the authors would like to thank EPSRC for supporting this work with grant EP/I003010/1 and CD-adapco for providing the software STAR-CCM+. 


\section{REFERENCES}

[1] J. Buongiorno, "Can corrosion and CRUD actually improve safety margins in LWRs?," Annals of Nuclear Energy, vol. 63, pp. 9-21, Jan 2014.

[2] P. Bennett, B. Beverskog, and R. Suther, "Halden in-reactor Test to Exhibit PWR Axial Offset Anomaly," EPRI, vol. 1008106, 2004.

[3] P. Cohen, "Heat and mass transfer for boiling in porous deposits with chimneys," AICHE Symposium Series, vol. 70, pp. 71-80, 1974.

[4] J. Deshon, "PWR Axial Offset Anamoly (AOA) Guidelines," EPRI, vol. 1008102, 2004.

[5] J. Mahlon, "The Simulation and Study of Conditions Leading to Axial Offset Anomaly in Pressurized Water Reactors," M.Sc., Georgia Institute of Technology, USA, 2004.

[6] I. ul Hag, N. Cinosi, M. Bluck, G. Hewitt, and S. Walker, "Modelling heat transfer and dissolved species concentrations within PWR crud," Nuclear Engineering and Design, vol. 241, pp. 155-162, Jan 2011.

[7] J. Henshaw, J. C. McGurk, H. E. Sims, A. Tuson, S. Dickinson, and J. Deshon, "A model of chemistry and thermal hydraulics in PWR fuel crud deposits," Journal of Nuclear Materials, vol. 353, pp. 1-11, Jul 2006.

[8] Y. Solomon and J. Roesmer, "MEASUREMENT OF FUEL-ELEMENT CRUD DEPOSITS IN PRESSURIZED WATER REACTORS," Nuclear Technology, vol. 29, pp. 166-173, 1976.

[9] S. Beltz, B. Liu, Z. Karoutas, and Asme, CFD MODELING OF FUEL ROD HEAT TRANSFER TO AID IN THE RISK ASSESSMENT OF FUEL ROD FAILURE DUE TO LOCALIZED CRUD. New York: Amer Soc Mechanical Engineers, 2009.

[10] M. A. Krammen, G. Q. Wang, S. F. Grill, Z. E. Karoutas, M. Y. Young, and Asme, METHODS FOR MODELING LOCAL FUEL ROD CRUD AND ASSESSING FAILURE RISK. New York: Amer Soc Mechanical Engineers, 2009.

[11] G. Wang, W. A. Byers, M. Y. Young, and M. A. Krammen, "Methods to reduce CIPS/CILC risk for the "Zero fuel failure by 2010" initiative," in 18th International Conference on Nuclear Engineering (ICONE 18), X'ian, China, 2010.

[12] R. V. Macbeth, "Boiling on surfaces overlayed with a porous deposit: heat trans- fer rates obtained by capillary action," Atomic Energy Establishment Winfrith, vol. AEEWR-711, 1971.

[13] C. Pan, B. G. Jones, and A. J. Machiels, "Wick Boiling Performance in Porous Deposits with Chimneys," AICHE/ANS National Heat Transfer Conference Symposium on Multiphase and Heat Transfer, 1985.

[14] W. A. Byers, Pressurized Water Reactor core crud mapping. New York: Amer Soc Mechanical Engineers, 2010.

[15] J. Nikuradse, "Law of Flow in Rough Pipes," NACA technical memorandum 1292, vol. 1291, 1950.

[16] H. Schlichting, Boundary-layer theory, 8th rev.\& enl.ed ed. Berlin

London: Springer, 2000.

[17] T. Cebeci, Momentum transfer in boundary layers. London: Hemisphere McGraw-Hill, 1977.

[18] "STAR-CCM+ user guide, version 7.06," CD-ADAPCO2012.

[19] V. C. Patel, W. Rodi, and G. Scheuerer, "TURBULENCE MODELS FOR NEAR-WALL AND LOW REYNOLDS-NUMBER FLOWS - A REVIEW," Aiaa Journal, vol. 23, pp. 1308-1319, 1985.

[20] M. E. Conner, E. Baglietto, and A. M. Elmahdi, "CFD methodology and validation for single-phase flow in PWR fuel assemblies," Nuclear Engineering and Design, vol. 240, pp. 2088-2095, Sep 2010.

[21] A. F. Mills, Heat transfer, 2nd ed. Upper Saddle River: Prentice Hall, 1999. 
[22] N. Cinosi, I. Haq, M. Bluck, and S. P. Walker, "The effective thermal conductivity of crud and heat transfer from crud-coated PWR fuel," Nuclear Engineering and Design, vol. 241, pp. 792-798, Mar 2011.

[23] J. Jimenez, "Turbulent flows over rough walls," Annual Review of Fluid Mechanics, vol. 36, pp. 173-196, 2004.

\section{APPENDIX}

\section{Derived quantities}

The sub-channel Reynolds number is obtained as:

$\operatorname{Re}=\frac{\mathrm{v} \rho D_{H}}{v}$

where $v$ is the average axial velocity, $\rho$ is the fluid density, $v$ is the fluid viscosity and $D_{H}$ is the sub-channel equivalent hydraulic diameter.

The wall shear stress is defined as:

$\tau_{w}=\frac{\rho \mathrm{v}^{2} f}{8}$

where $f$ is the Darcy friction factor, estimated through the Haarland approximation [23].

The friction velocity is defined as:

$u^{*}=\sqrt{\frac{\tau_{w}}{\rho}}$

The wall $y^{+}$is obtained as:

$y^{+}=\frac{y u^{*}}{v}$

where $y$ is the distance between the wall and the centre of the volume cell of interest, $u^{*}$ is the friction velocity.

\section{W3 (Tong) correlation for critical heat flux}

The critical heat flux is a function of inlet sub-cooling, pressure and coolant mass flux, as:

$\dot{q}_{c}=K_{1}\left(P, x_{e}\right) \cdot K_{2}\left(x_{e}, J\right) \cdot K_{3}\left(D_{H}\right) \cdot K_{4}\left(h_{i n}\right)$

where:

$K_{1}\left(P, x_{e}\right)=\left\{(2.022-0.06238 P)+(0.1722-0.01427 P) \exp \left[(18.177-0.5987 P) x_{e}\right]\right\}$. $\cdot\left[1.157-0.869 x_{e}\right]$ 


$$
\begin{aligned}
& K_{2}\left(x_{e}, J\right)=\left[\left(0.1484-1.596 x_{e}+0.1729 x_{e}\left|x_{e}\right|\right) \cdot 2.326 J+3271\right] \\
& K_{3}\left(x_{e}, D_{H}\right)=\left[0.2664+0.8357 \exp \left(-124.1 D_{H}\right)\right] \\
& K_{4}\left(h_{i n}\right)=\left[0.8258+0.0003413\left(h_{\text {sat }}-h_{i n}\right)\right]
\end{aligned}
$$

Definition of symbols:

\begin{tabular}{|c|c|l|}
\hline$\dot{q}_{c}$ & $\mathrm{~kW} / \mathrm{m}^{\wedge} 2$ & critical heat flux \\
\hline$P$ & $\mathrm{MPa}$ & pressure \\
\hline$x_{e}$ & & local quality \\
\hline$D_{H}$ & $\mathrm{~m}$ & equivalent hydraulic diameter \\
\hline$J$ & $\mathrm{~kg} / \mathrm{m}^{\wedge} 2 . \mathrm{s}$ & mass flux \\
\hline$h_{s a t}$ & $\mathrm{~kJ} / \mathrm{kg}$ & saturated liquid enthalpy \\
\hline$h_{\text {in }}$ & $\mathrm{kJ} / \mathrm{kg}$ & inlet enthalpy \\
\hline
\end{tabular}

Eq. A 1 is valid in the range:

$$
\begin{aligned}
& 5.5<P<16 \mathrm{MPa} \\
& 1356<J<6800 \mathrm{~kg} / \mathrm{m}^{2} s \\
& 1.2<D_{H}<1.8 \mathrm{~cm} \\
& -0.15<x_{e}<+0.15
\end{aligned}
$$

The correlation in Eq. A 1 is for CHF in uniformly heated channels. To account for non-uniform heat fluxes a correction factor $F$ is introduced: $\dot{q}_{c, N}=\dot{q}_{c} / F$. However, in the present paper the computed $F$ appears to be next to unity, so Eq. A 1 provides a realistic approximation of the CHF.

\section{Algorithm applied to compute DNBR}

The margin between the heat flux and the CHF is the DNB Ratio (DNBR), defined as the ratio of the critical the heat flux at a specific location and the operating heat flux at that location:

$D N B R=\frac{\dot{q}_{c}}{\dot{q}\left(l_{c}\right)}$

where $l_{c}$ is the axial location in the channel where DNB occurs.

The DNBR is computed as following:

1. Select an axial location $l_{c}$ at which to compute the CHF 
2. Compute the local enthalpy $h_{s a t}$ and quality $x_{e}$ at this location. For a single channel they are:

$$
\begin{aligned}
& h_{c}=h_{i n}+\frac{1}{G} \int_{0}^{l_{c}} \dot{q}(z) \pi D_{H} d z \\
& x_{e}=\frac{h_{c}-h_{s a t}}{h_{f g}} \\
& h_{f g} \text { is the specific enthalpy of evaporation }
\end{aligned}
$$

3. Compute $\dot{q}_{c}$ from the W3 correlation, Eq. A 1 .

4. Compute the DNBR from Eq. A 2. $\dot{q}\left(l_{c}\right)$ Is the local operating heat flux.

5. Increase $l_{c}$ and repeat from step 1 over the entire channel 